\title{
Inequalities in Young Adult Health Insurance Coverage Post-federal Health Reform
}

\author{
Lauren E. Wisk, $P h D^{7}$ and Niraj Sharma, MD, MPH',3,4 \\ 'Division of Adolescent/Young Adult Medicine, Boston Children's Hospital and Department of Pediatrics, Harvard Medical School, Boston, MA, \\ USA; ${ }^{2}$ Division of General Medicine, Department of Medicine, Brigham and Women's Hospital, Boston, MA, USA; ${ }^{3}$ Division of General Pediatrics, \\ Department of Pediatrics, Boston Children's Hospital, Boston, MA, USA; ${ }^{4}$, Harvard Medical School, Boston, MA, USA.
}

\begin{abstract}
BACKGROUND: Uninsurance for young adults (YAs) was greatly reduced by the Affordable Care Act (ACA). However, reforms may not be equally beneficial for all YAs and certain policies may exacerbate, rather than resolve, preexisting disparities.
\end{abstract}

OBJECTIVE: To investigate inequalities in YAs' insurance coverage pre- (2000-2010) and post-federal health reforms (dependent coverage expansion, 2010-2013, and Medicaid/Marketplace expansions, 2014-2016), among a nationally representative sample.

DESIGN: A difference-in-differences estimator (controlling for sociodemographics) was used to determine the effects of the ACA for young adults (ages 19-25) compared to adolescents (ages 13-18) and older YA (ages 26-30) counterparts; triple-difference estimators quantified differential policy effects by sociodemographics.

PARTICIPANTS: Three hundred eighty-seven thousand six hundred thirty-five participants in the 2000-2016 National Health Interview Survey.

MAIN MEASURES: Respondents reported their health insurance coverage types during the last 12 months, reasons uninsured, and detailed sociodemographics. KEY RESULTS: An adjusted difference-in-differences estimator quantified a 12.3 percentage point increase $(p<0.0001)$ in full-year coverage post-ACA for YAs compared to older counterparts, driven by increases in employer-sponsored private insurance while younger and older youth saw larger gains in Medicaid coverage. Triple-difference estimators identified subgroups experiencing less beneficial dependent coverage expansion effects, including females, lower socioeconomic status, non-citizens, non-English speakers, and several racial/ ethnic minority groups. Later ACA reforms (Marketplace/ Medicaid expansions) mitigated many of these widening disparities.

CONCLUSION: While the ACA significantly impacted YA insurance coverage, these gains were not of equal magnitude for all YAs and disparities remain. As such, more work needs to be done to ensure optimal and equitable access to high-quality, affordable insurance for all YAs.

KEY WORDS: insurance coverage; National Health Policy; health care disparities; adolescence; young adult.

Received June 8, 2018

Revised August 30, 2018

Accepted October 18, 2018

Published online November 14, 2018
J Gen Intern Med 34(1):65-74

DOI: $10.1007 / \mathrm{s} 11606-018-4723-0$

(C) Society of General Internal Medicine 2018

\section{INTRODUCTION}

Since the implementation of the Patient Protection and Affordable Care Act (ACA) in 2010, the overall uninsured rate in the United States (US) decreased to an all-time low. By 2016, the uninsured rate among all Americans dropped to $9 \%$ and to $10.4 \%$ for those under the age of 65. ${ }^{1}$ As young adults (YAs, ages 19-25) traditionally experienced the highest rates of uninsurance compared to both younger and older counterparts, ${ }^{2,3}$ the ACA included specific provisions to address the unique coverage needs of YAs. The dependent coverage expansion provision, which allowed young adults to remain on their parents' insurance plans until they turn age 26, led to a decrease in the number of YAs without health insurance ${ }^{4}$ and allowed many YAs to obtain employer-sponsored insurance (ESI) coverage post-implementation. ${ }^{5}$ However, in the 7 years since the ACA has been implemented, it is unclear if coverage has improved equally for all YAs, including those of lower socioeconomic status (SES) who may be less likely to benefit from these policies. Yet, YAs who may not be able to take advantage of the dependent coverage provision may still have new, affordable coverage options via the ACA's Medicaid expansion ${ }^{6}$ or through the health insurance exchanges (Marketplaces).

Though there is some evidence on disparities in insurance coverage gains post-reform ${ }^{7-13}$-including one study that characterized racial/ethnicity disparities for $\mathrm{YAs}^{14}$ - knowledge gaps remain regarding the magnitude and direction (i.e., widening vs. shrinking) of inequalities across several vulnerable groups and the extent to which specific reform policies may differentially affect coverage options and uptake among subgroups. To address these gaps, the purpose of this study is to investigate inequalities in health insurance coverage among YAs pre- and post-implementation of specific provisions of the ACA and to quantify disparities among hypothesized vulnerable subgroups. 


\section{METHODS}

\section{Data Source and Population}

Data are from the National Health Interview Survey (NHIS), which collects health information annually for a nationally representative, cross-sectional sample of the civilian, noninstitutionalized population in the US; we obtained NHIS data from the IPUMS database. ${ }^{15}$ Our sample included 387,635 adolescents/young adults, ages 13-30 years, who were interviewed in one of 17 NHIS years, from 2000 to 2016, and had complete data for outcomes of interest. As data are already collected and de-identified, this study was deemed exempt by Institutional Review Board.

\section{Measures}

Health Insurance. NHIS respondents report their current health insurance coverage at the time of the survey, followed by detailed questions about each coverage type (including follow-up questions to evaluate the reliability of the reported coverage and to adjudicate conflicting information) and duration of coverage during the past 12 months. We created several summary measures of insurance coverage during the past 12 months, including time with coverage (full-year insured, partial-year insured, full-year uninsured) and type of coverage (e.g., private coverage, government/public coverage), relying on Current Population Survey definitions to operationalize coverage types. ${ }^{16}$ We further investigated the type of coverage by source (e.g., employer-sponsored insurance, insurance obtained through the health insurance exchanges, Medicaid, etc.) and reasons for lack of insurance among those without coverage at the time of the survey. Beginning in 2014, several new questions were added to capture health care coverage obtained through the Health Insurance Marketplace or state-based exchanges; insurance obtained through Marketplaces was treated as non-group market coverage. In 2011, questions were added to clarify the relationship of the covered individual to the policyholder (e.g., dependent); we evaluated the magnitude of policy effects on employer-sponsored coverage generally and that provided specifically to a dependent beneficiary.

Sociodemographics. We compiled data on several sociodemographic characteristics, including sex, detailed race/ethnicity, citizenship status (born in the US, legal/ naturalized citizens, non-citizens, unreported), interview language (English only, any other language, unreported), educational attainment (we preferentially used highest parental education; most respondents reported their parents' attainment and relied on own educational attainment when parent information was absent), total combined income of all family members as a percentage of the federal poverty level (FPL), US region of residence (Northeast, Midwest, South, West), and special health care needs. Detailed race/ethnicity categories included White (non-Hispanic, $\mathrm{nH})$, Black (nH), Chinese (nH), Filipino (nH), Asian Indian (nH), other Asian (nH), American Indian/Alaska
Native $(\mathrm{nH})$, other race $(\mathrm{nH})$, multiple races $(\mathrm{nH})$, MexicanAmericans (the largest Hispanic subgroup), and other Hispanic. We identified individuals who reported any limitation in one or more activities assessed by the NHIS (e.g., activities of daily living, cognitive impairment) as having a special health care need (SHCN). Despite a more narrow conceptualization of health care needs (which does not necessarily include every respondent with a chronic medical condition), we used this definition because it was available for all respondents and consistently assessed across the range of ages included in our target population (i.e., both $\leq 17$ years and $\geq 18$ years).

\section{Analytic Approach}

We employed a pre-post comparison design, basing periods on the survey interview dates to isolate a pre-reform period prior to enactment of the ACA (Jan 2000-Feb 2010), a period capturing enactment of the dependent coverage expansion (DCE) provision of the ACA (Mar 2010-Dec 2013), ${ }^{1}$ and a period capturing subsequent establishment of health insurance exchanges (Marketplaces) and expansion of Medicaid (Jan 2014Dec 2016). Because we were interested in full-year coverage as an outcome, we tested the inclusion/exclusion of a 1-year run-in period at the beginning of each post-reform window; results were consistent across this specification and models adjusting for the run-in period are shown.

We used a difference-in-differences (DID) estimator to determine federal policy effects on insurance coverage for young adults (YAs, ages 19-25) compared against both adolescents (ages 13-18) and older young adults (ages 26-30) separately. All models additionally adjusted for age, year, sex, race/ethnicity, citizenship status, language, education, income, region, and SHCN. We further utilized a triple-difference, or difference-in-difference-in-differences (DDD), estimator to investigate the potential for effect heterogeneity of reform effects across individual characteristics. Specifically, we evaluated the possibility of interactions between the DID estimator and several sociodemographics to estimate if the magnitude of policy effects varied by these sociodemographic characteristics (e.g., if the policy effect was greater for males vs. females). We compared annual trends in coverage outcomes in the prereform period (testing the parallel trends assumption) by age, finding no evidence of differences for non-group market coverage or Medicaid coverage but converging trends for employer-sponsored coverage.

We employed binary or multinomial logistic regression to model insurance coverage outcomes; all regression models adjusted for aforementioned sociodemographic characteristics. Marginal predicted probabilities were output from regression models and used to convey the absolute magnitude of policy effects; the cumulative ACA change was calculated by

\footnotetext{
${ }^{1}$ Though the ACA's dependent coverage expansion was enforced for nongrandfathered plans beginning or renewing on/after September 23, 2010, plans could voluntarily comply with these requirements prior to that date, so we began our post-dependent coverage period after the ACA was signed into law on March 23, 2010.
} 
summing the post-dependent coverage change and postexpansion change (both relative to pre-ACA). All analyses accounted for the complex, multistage probability sampling design of the NHIS, incorporating stratification, clustering, and unequal household selection probabilities. Descriptive statistics for sample characteristics and sociodemographics by age groups are shown in Appendix Table 2.

\section{RESULTS}

From 2000 to 2016, the unadjusted prevalence of full-year insurance coverage among adolescents (ages 13-18) increased by 8.1 percentage points (pp) and by $6.2 \mathrm{pp}$ for older YAs (ages 26-30) while coverage increased by 20.5 pp for YAs (Fig. 1; all $p<0.0001$ ). Correspondingly, there were precipitous drops in full-year uninsurance among YAs $\left(20.8 \%\right.$ in 2000 to $8.2 \%$ in $2016, p_{\text {trend }}<$ $0.0001)$ and partial-year coverage $(18.8 \%$ in 2000 to $11.0 \%$ in $\left.2016, p_{\text {trend }}<0.0001\right)$. Adjusted analyses revealed that the dependent coverage expansion was associated with an $8.6 \mathrm{pp}$ increase in full-year coverage for YAs, compared to a $3.3 \mathrm{pp}$ decrease for older YAs during the same period (DID + $11.9 \mathrm{pp}$ for YAs vs. older YAs, all $p<0.0001$, Table 1); YA coverage gains corresponded to a $4.9 \mathrm{pp}$ and $3.3 \mathrm{pp}$ reduction in partial-year coverage and full-year uninsurance, respectively (both $p<0.0001$, data not shown). Increases in employer-sponsored private insurance drove coverage gains for YAs $(+13.0 \mathrm{pp}$ post-DCE, Table $1 ;+14.8 \mathrm{pp}$ for employer-sponsored dependent coverage, data not shown) while adolescents and older YAs saw larger gains in Medicaid coverage post-expansion (Table 1). Post-ACA, YAs saw a $6.6 \mathrm{pp}$ reduction in reporting a lack of insurance due to age ineligibility (or because of leaving school) but this endorsement simultaneously increased among older YAs; similar findings were observed for uninsurance due to a major life event. While there were sizable reductions in citing cost as a reason for being uninsured across all ages, YAs experienced lesser reductions $(4.2 \mathrm{pp})$ than did their younger and older counterparts (13.3 pp and $6.9 \mathrm{pp}$, respectively).

Investigation into potential reform effect heterogeneity (Fig. 2) revealed that males saw greater improvements in full-year insurance than females-helping to close the prior gap in coverage - but several subgroups experienced significantly smaller (i.e., less beneficial) dependent coverage expansion effects, including lower SES (education and income), non-US citizens, those whose primary language was not English, and several minority groups. In some cases, these differential effects resulted in widening inequalities in coverage for YA post-DCE (e.g., 7.2 pp exacerbation for Black nonHispanic, 9.2 pp exacerbation for those with some college but no degree, and approximately 6 to 9 pp exacerbation for those making $<200 \%$ FPL); though in many cases of exacerbation in inequalities post-DCE, differences were at least partially mitigated by subsequent gains from Marketplace and Medicaid expansions (e.g., 3.3 pp improvement for Black nonHispanic, $4.6 \mathrm{pp}$ improvement for those with some college but no degree, and approximately 9 to $14 \mathrm{pp}$ improvement for those making $<200 \%$ FPL).

\section{DISCUSSION}

During a period of substantial federal health reform, groups at peak risk for "falling through the cracks" exhibited substantial absolute gains in insurance coverage. Nevertheless, some gains were not uniform across groups. Rather our data suggest widening inequities in private coverage for minority YAs, non-citizens, YAs speaking English as a second language, those without a college degree, and YAs in families making $<300 \%$ FPL, while shrinking for males and YAs without SHCN. Later ACA reforms, including Medicaid and Marketplace expansions, appear to be critically important for providing alternative coverage sources for vulnerable groups and mitigating inequities that grew with the dependent coverage expansion. Findings suggest that continued attention and advocacy regarding new/remaining disparities, particularly among socioeconomically vulnerable and minority YAs, is warranted post-reform.

A known caveat to the federal dependent coverage expansion is that only YAs whose parent(s)/guardian(s) have access to an affordable, private/commercial insurance plan stand to benefit from this policy. ${ }^{17}$ Our findings support the hypothesis that the salutary effects of the dependent coverage expansion were indeed smaller for YAs who may be less likely to have access to affordable family coverage. For instance, less efficacious policy effects were noted for YAs in lower income families, potentially because the inclusion of a YA dependent would substantially raise their family's premium or because they lacked access to any family policy. Even with the "family glitch" (families' eligibility for Marketplace subsidies is based on premiums associated with an individual- rather than family-level ESI policy) potentially diminishing the availability of dependent coverage options for lower SES YAs, Marketplaces may contemporaneously help to mollify this barrier to affordable private coverage for YAs who apply for subsidized coverage on their own (and thus would not be penalized for their parents' income). Yet, poor understanding of health insurance and confusion in navigating this new platform may still lessen this potential benefit for YAs, ${ }^{18}$ perhaps explaining why YAs saw smaller gains in non-group market coverage than older YAs.

Medicaid expansions also had the potential to provide new coverage options for many lower income YAs, and we find that these later policies resulted in small gains in Medicaid coverage for YAs (but these gains were also smaller than those for older YAs). Even though the overall coverage gains for YAs due to later reforms were relatively small, these policies (Marketplaces and Medicaid expansion) played an important role in counteracting the 

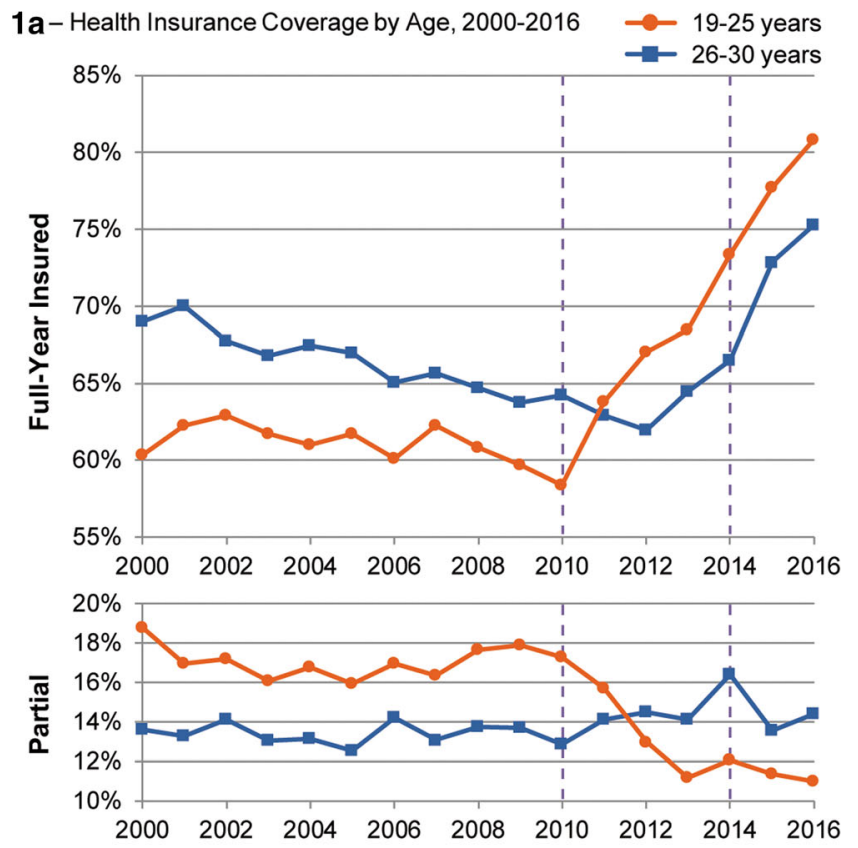

1b- Health Insurance Coverage by Age, 2000-2016 - 19-25 years
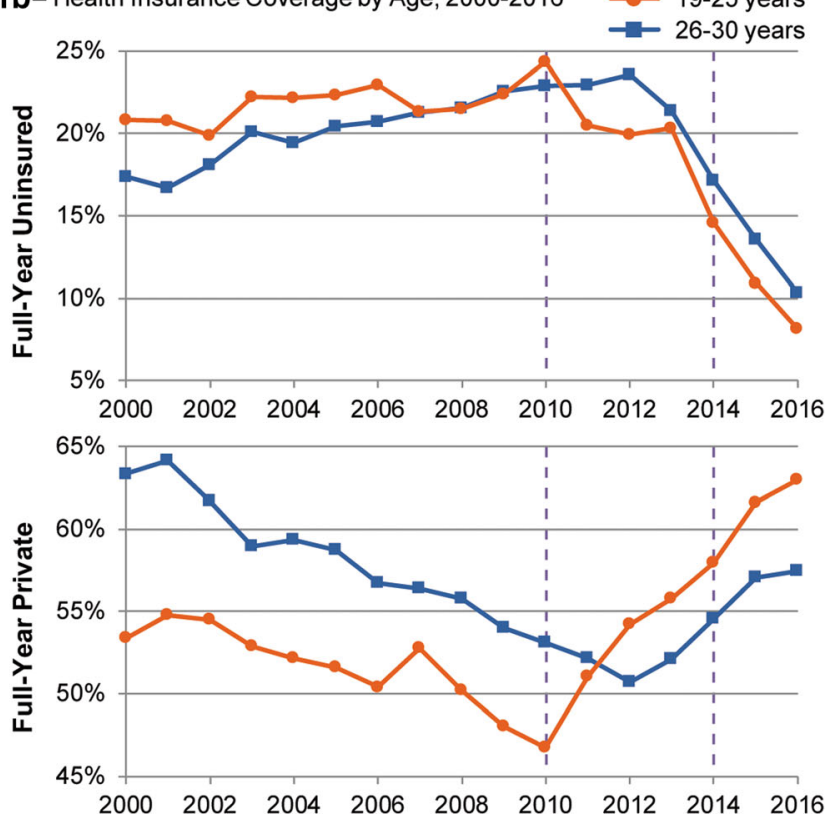

Figure 1 a-c Health insurance coverage by age, 2000-2016. Points depict unadjusted prevalence of health insurance coverage by age group (ages 19-25 years in orange and ages 26-30 years in blue) during the study period (2000-2016). Full-year coverage; partialyear coverage; full-year uninsured; full-year private; full-year employer-sponsored insurance; full-year non-group market coverage, including coverage obtained on the health insurance exchanges; and full-year Medicaid coverage are shown.

widening of disparities that emerged after dependent coverage expansion. In fact, the only subgroups that experienced a substantial widening of disparities after these later expansions were YAs in the Midwest and South, both regions of the country where states were least likely to expand Medicaid or implement robust state-based health insurance exchanges. Together, these findings highlight the

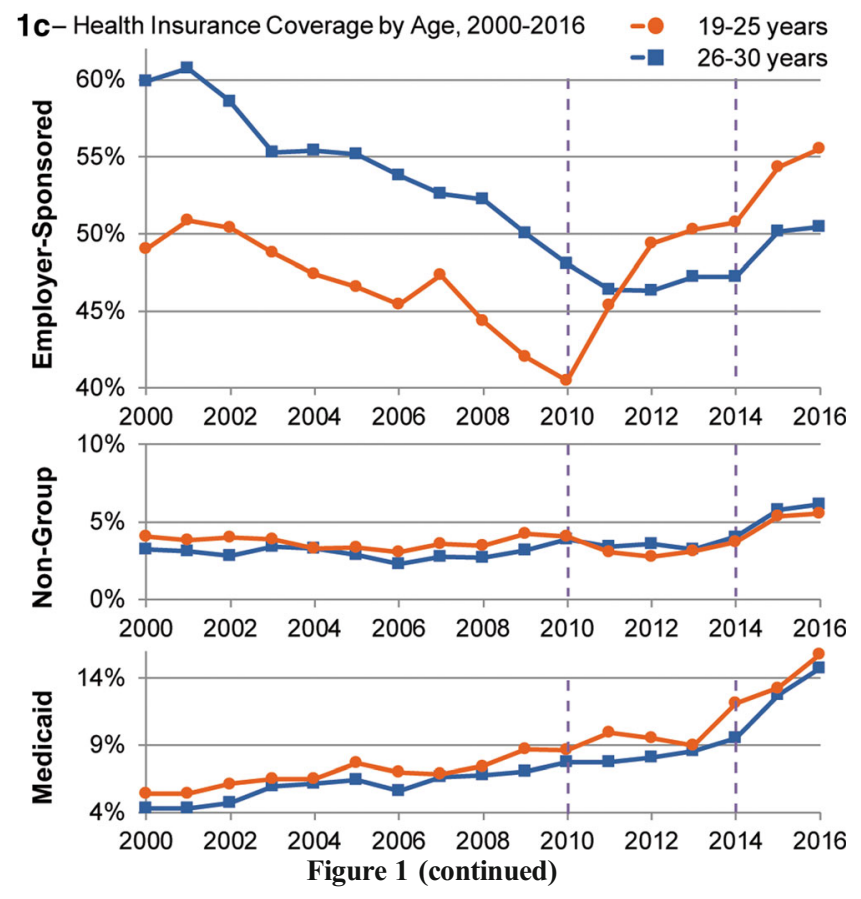

utility of these later policies for closing coverage gaps that were unintentionally introduced by an otherwise helpful policy. Beneficial impacts notwithstanding, universal coverage exists as a uniform solution for equalizing access to coverage rather than continuing piecemeal policies each designed to expand access to a different coverage source and with varying success in doing so equitably.

Existing evidence identified that dependent coverage expansion policies may provide financial protection for $\mathrm{YAs}^{19-22}$ and are associated with positive gains in access to care and some health outcomes ${ }^{8,23-29}$ and additional research has shown similar Medicaid expansion effects. ${ }^{6,30}$ Although all youths were less likely to cite cost as a reason for being uninsured post-reform, we observed a greater reduction in cost-related uninsurance for adolescents and older YAs than for YAs, and these effects were primarily observed in the early post-reform period. Co-occurring ACA provisions (e.g., preventing insurers from denying children coverage because of preexisting conditions or restrictions on annual and lifetime coverage limits) may be responsible for these gains, but given that these effects do not persist for YAs in the later reform period, it may be more likely that they are the result of general economic gains post-recession. Still, as private coverage may not fully protect against a high cost burden, particularly for lower income families, ${ }^{31-33}$ the specific impact of the ACA's consumer protection provisions on access to both insurance and care for YAs warrants further investigation.

Despite the gains in coverage, allowing YAs to maintain dependent coverage may have unintended negative consequences-namely, a delayed "adulting cliff." We found a substantial reduction in lack of insurance 
Table 1 Health Reform Effects on Health Insurance Coverage

\begin{tabular}{|c|c|c|c|c|c|c|c|c|c|}
\hline & \multicolumn{6}{|c|}{ Full-year insurance coverage type } & \multicolumn{3}{|c|}{ Reason uninsured } \\
\hline & $\begin{array}{l}\text { Any source } \\
(\%)\end{array}$ & $\begin{array}{l}\text { Private } \\
(\%)\end{array}$ & $\begin{array}{l}\text { Employer- } \\
\text { sponsored } \\
(\%)\end{array}$ & $\begin{array}{l}\text { Non- } \\
\text { group } \\
\text { market } \\
(\%)\end{array}$ & $\begin{array}{l}\text { Government- } \\
\text { sponsored } \\
(\%)\end{array}$ & $\begin{array}{l}\text { Medicaid } \\
(\%)\end{array}$ & $\begin{array}{l}\text { Ineligible } \\
\text { due to } \\
\text { age/school } \\
(\%)\end{array}$ & $\begin{array}{l}\text { Major life } \\
\text { event }(\%)\end{array}$ & $\begin{array}{l}\text { Cost is } \\
\text { too high } \\
(\%)\end{array}$ \\
\hline \multicolumn{10}{|c|}{ Pre-ACA coverage estimates and $95 \%$ confidence intervals } \\
\hline $13-18$ years & $\begin{array}{l}80.8 \\
(79.5-82.0)\end{array}$ & $\begin{array}{l}47.2 \\
(45.3-49.2)\end{array}$ & $\begin{array}{l}40.0 \\
(38.2-41.8)\end{array}$ & $\begin{array}{l}2.2 \\
(1.8-2.6)\end{array}$ & $\begin{array}{l}21.4 \\
(19.7-23.1)\end{array}$ & $\begin{array}{l}9.1 \\
(8.2-10.2)\end{array}$ & $\begin{array}{l}1.4 \\
(1.1-1.7)\end{array}$ & $\begin{array}{l}4.4 \\
(3.7-5.2)\end{array}$ & $\begin{array}{l}52.8 \\
(49.2-56.4)\end{array}$ \\
\hline 19-25 years & $\begin{array}{l}60.6 \\
(59.0-62.2)\end{array}$ & $\begin{array}{l}34.2 \\
(32.5-35.9)\end{array}$ & $\begin{array}{l}27.6 \\
(26.1-29.1)\end{array}$ & $\begin{array}{l}2.4 \\
(2.0-2.8)\end{array}$ & $\begin{array}{l}11.9 \\
(10.9-12.9)\end{array}$ & $\begin{array}{l}5.2 \\
(4.7-5.8)\end{array}$ & $\begin{array}{l}15.8 \\
(13.6- \\
18.3)\end{array}$ & $\begin{array}{l}23.8 \\
(21.4-26.3)\end{array}$ & $\begin{array}{l}39.7 \\
(36.8-42.7)\end{array}$ \\
\hline $26-30$ years & $\begin{array}{l}69.8 \\
(68.1-71.4)\end{array}$ & $\begin{array}{l}37.4 \\
(35.4-39.4)\end{array}$ & $\begin{array}{l}31.4 \\
(29.7-33.2)\end{array}$ & $\begin{array}{l}1.9 \\
(1.5-2.3)\end{array}$ & $\begin{array}{l}16.8 \\
(15.4-18.3)\end{array}$ & $\begin{array}{l}7.5 \\
(6.7-8.5)\end{array}$ & $\begin{array}{l}8.9 \\
(7.4-10.6)\end{array}$ & $\begin{array}{l}15.7 \\
(13.8-17.8)\end{array}$ & $\begin{array}{l}43.2 \\
(39.9-46.4)\end{array}$ \\
\hline \multicolumn{10}{|c|}{ Post-dependent coverage expansion effect } \\
\hline $\begin{array}{l}13-18 \text { years } \\
19-25 \text { years }\end{array}$ & $\begin{array}{l}+4.41 * * * \\
+8.61 * * *\end{array}$ & $\begin{array}{l}-0.98 \\
+13.34 * * *\end{array}$ & $\begin{array}{l}0.64 \\
+13.03 * * *\end{array}$ & $\begin{array}{l}-0.14 \\
- \\
0.52 * * *\end{array}$ & $\begin{array}{l}+1.88 * * * \\
-1.64 * * *\end{array}$ & $\begin{array}{l}+1.40 * * * \\
-0.86 * * *\end{array}$ & $\begin{array}{l}-0.18 \\
-2.37 * * *\end{array}$ & $\begin{array}{l}-0.55 \\
-2.98 * * *\end{array}$ & $\begin{array}{l}-6.75^{* * * *} \\
-4.15^{* * *}\end{array}$ \\
\hline 26-30 years & $-3.29 * * *$ & $-1.81^{* *}$ & $-1.33 *$ & $+0.27 *$ & -0.94 & $-0.69 *$ & $+4.97 * * *$ & $+5.24 * * *$ & $-7.74 * * *$ \\
\hline \multicolumn{10}{|c|}{ Post-Medicaid and Marketplace coverage expansion effect (incremental) } \\
\hline $13-18$ years & $+3.77 * * *$ & $+3.52 * * *$ & $+1.84 * *$ & + & -0.13 & $+2.84 * * *$ & +0.11 & -0.11 & $-6.55^{* *}$ \\
\hline 19-25 years & $+11.40 * * *$ & $+9.86^{* * *}$ & $+7.13 * * *$ & $\begin{array}{l}+ \\
1.74 * * *\end{array}$ & $+2.84 * * *$ & $+2.75 * * *$ & $-4.26 * * *$ & $-5.49 * * *$ & -0.05 \\
\hline $26-30$ years & $+11.04 * * *$ & $+8.67 * * *$ & $+5.67 * * *$ & $\begin{array}{l}+ \\
1.63 * * *\end{array}$ & $+5.72 * * *$ & $+4.90 * * *$ & $-2.05^{* *}$ & $-3.50 * * *$ & +0.84 \\
\hline \multicolumn{10}{|c|}{ Total ACA effect (cumulative) } \\
\hline 13-18 years & $+8.18 * * *$ & $+2.54 * *$ & $+2.48 * *$ & $\begin{array}{l}+ \\
1.02 * * *\end{array}$ & $+1.75^{*}$ & $+4.24 * * *$ & -0.07 & -0.66 & $-13.30 * * *$ \\
\hline 19-25 years & $+20.01 * * *$ & $+23.20 * * *$ & $+20.16^{* * *}$ & $+2.22 * * *$ & $+1.20 *$ & $+1.89 * * *$ & $-6.63 * * *$ & $-8.47 * * *$ & $-4.20 * *$ \\
\hline $26-30$ years & $+7.75^{* * *}$ & $+6.86^{* * * *}$ & $+4.34 * * *$ & $\begin{array}{l}+ \\
1.89 * * *\end{array}$ & $+4.78 * * *$ & $+4.21 * * *$ & $+2.92 * * *$ & +1.74 & $-6.90 * * *$ \\
\hline \multicolumn{10}{|c|}{ DID effect (ages $19-25$ vs. $26-30$ ) } \\
\hline $\begin{array}{l}\text { Dependent } \\
\text { coverage }\end{array}$ & $+11.90 * * *$ & $+15.15 * * *$ & $+14.36^{* * *}$ & $\overline{0.79 * * *}$ & $-0.70 * *$ & -0.17 & $-7.34 * * *$ & $-8.22 * * *$ & $+3.59 * *$ \\
\hline Total ACA & $+12.26 * * *$ & $+16.34 * * *$ & $+15.82 * * *$ & $-\overline{0.67 * * *}$ & $-3.58 * * *$ & $-2.32 * * *$ & $-9.55 * * *$ & $-10.21 * * *$ & +2.70 \\
\hline
\end{tabular}

ACA, Affordable Care Act; DID difference-in-differences

The table reports predicted probabilities obtained from multivariate models that regressed each insurance coverage outcome on age groups, reform period, an interaction between age groups and reform period, and covariates (linear age, survey year, sex, racelethnicity, citizenship status, language, education, income, region, and special health care needs). Post-dependent coverage expansion effects are interpreted as the change in the adjusted probability of each outcome during the ACA's dependent coverage expansion, by age. Post-coverage expansion effects (incremental) are interpreted as the additional change (beyond that observed in the post-dependent coverage expansion period) in the adjusted probability of each outcome during the ACA's Medicaid and Marketplace expansion, by age. The total ACA effects (cumulative) are interpreted as the total change in the adjusted probability of each outcome after the ACA's implementation, by age, or sum of the prior two effects. In all cases, $p$ values indicate whether each effect is statistically different from zero after adjusting for all sociodemographic characteristics $(* p<0.10, * * p<0.05, * * * p<0.01)$

Difference-in-differences (DID) effects indicate the policy effects for 19-25-year-olds relative to that of 26-30-year-olds

Data are from the 2000-2016 National Health Interview Survey. All estimates are weighted to be nationally representative

because of age eligibility or a major life event for YA post-reform but a corresponding increase in reporting those same reasons for older YA post-reform. As the dependent coverage expansion allows youths to maintain coverage until age 26 , those who previously may have been dropped from their family plan at 22 may still experience insurance loss but only now delayed until age 26-pushing YAs off the "adulting cliff" at a slightly later age but perhaps when they are no less prepared to obtain coverage independently. Because of the crosssectional nature of our data, we cannot assess exactly when youth lose their dependent coverage or the type of or ease with which they acquire coverage thereafter. Future work should address whether 26 is in fact the most appropriate termination age for dependent coverage expansion policies or if young adult health and access to care $^{34,35}$ could be better served by extending this safety net further.

Finally, when interpreting disparity research, it is important to note both that lack of statistical differences for certain groups does not mean that disparities do not exist (simply that the un-confounded/independent effect of group membership is not the driver of the disparity), and that findings may exist on the absolute but not relative scale (or vice versa). ${ }^{36}$ Although we did not find that American Indians and Alaska Natives (AIAN, a population directly addressed in the $\mathrm{ACA}^{37}$ ) experienced a significantly different relative policy effect, this group still observed significantly lower rates of full-year insurance during the entire study period compared to their White counterparts. As such, our findings 
2a Among ages 19-25 years during: $\square$ pre-reform $\square$ post-all expansions (Exp+)
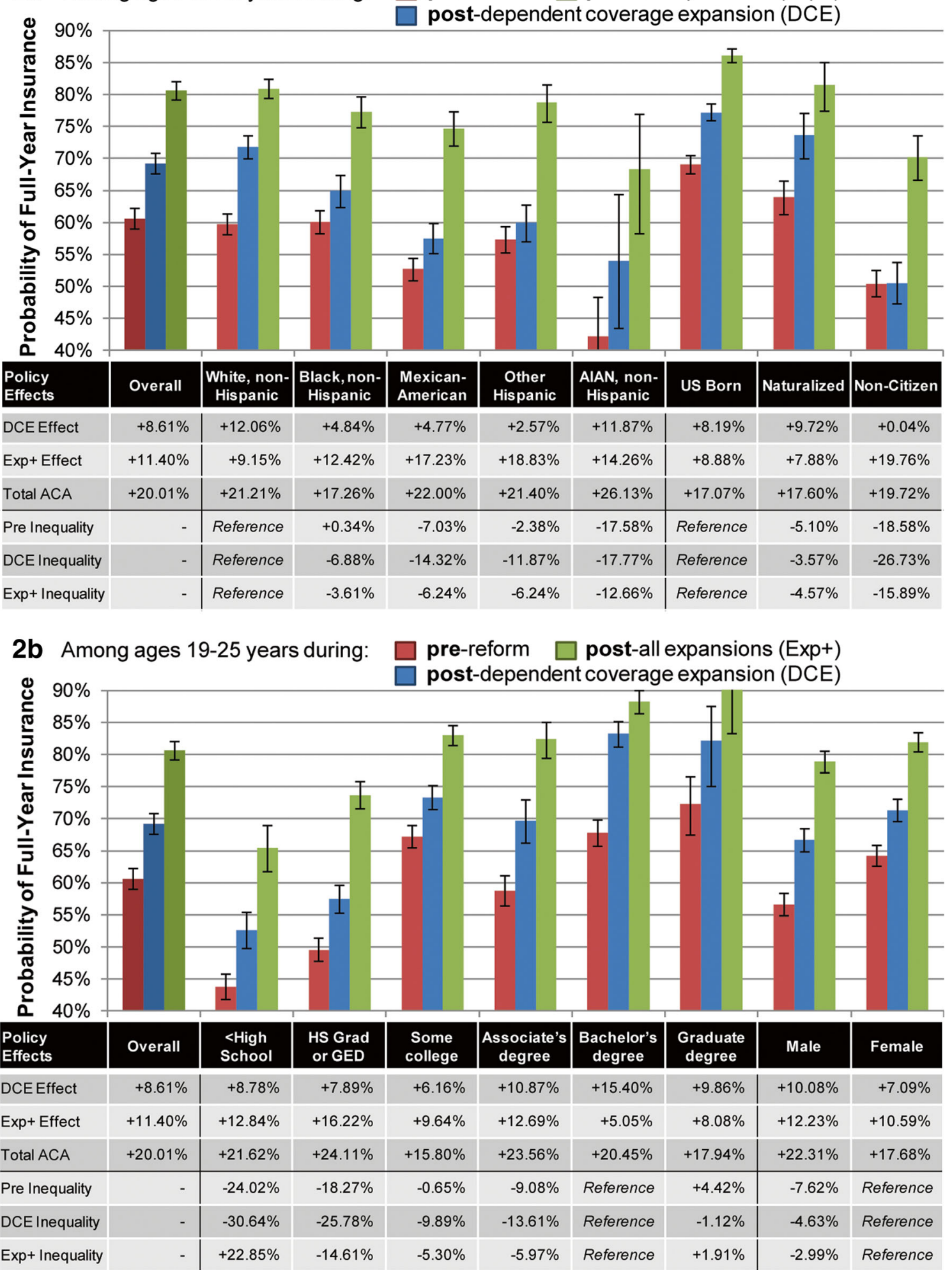

Figure 2 a-d Magnitude of policy effects on full-year insurance by sociodemographics. Marginal predicted probabilities of full-year health insurance coverage for youth ages 19-25 years across reform periods were output from fully adjusted multivariate triple-difference models; adjusted probability (colored bar) and the associated 95\% confidence intervals (error bars) for youth ages 19-25 overall and by selected sociodemographic characteristics are presented in the figure. The table below shows the absolute policy effects (difference in marginal probabilities) for ages 19-25 between the post-dependent coverage expansion (DCE) and pre-reform periods (DCE Effect), the post-all expansions (Exp+) and post-DCE periods (incremental Exp+ Effect), and post-Exp+ and pre-reform periods (Total Affordable Care Act, ACA, Effect). Additionally, period-specific inequities were calculated as the difference in marginal probabilities between each subgroup vs. the reference level (e.g., pre-reform inequity of $-7.03 \%$ in panel a describes that full-year insurance coverage was 7.03 percentage points lower for Mexican-Americans compared to their White, non-Hispanic counterparts, ages 19-25 years, during the pre-reform period). Inequities that diverge from zero (moving from pre- to post-reform) are increasing, while inequities that converge to zero are decreasing. AIAN, American Indian/Alaska Native. 

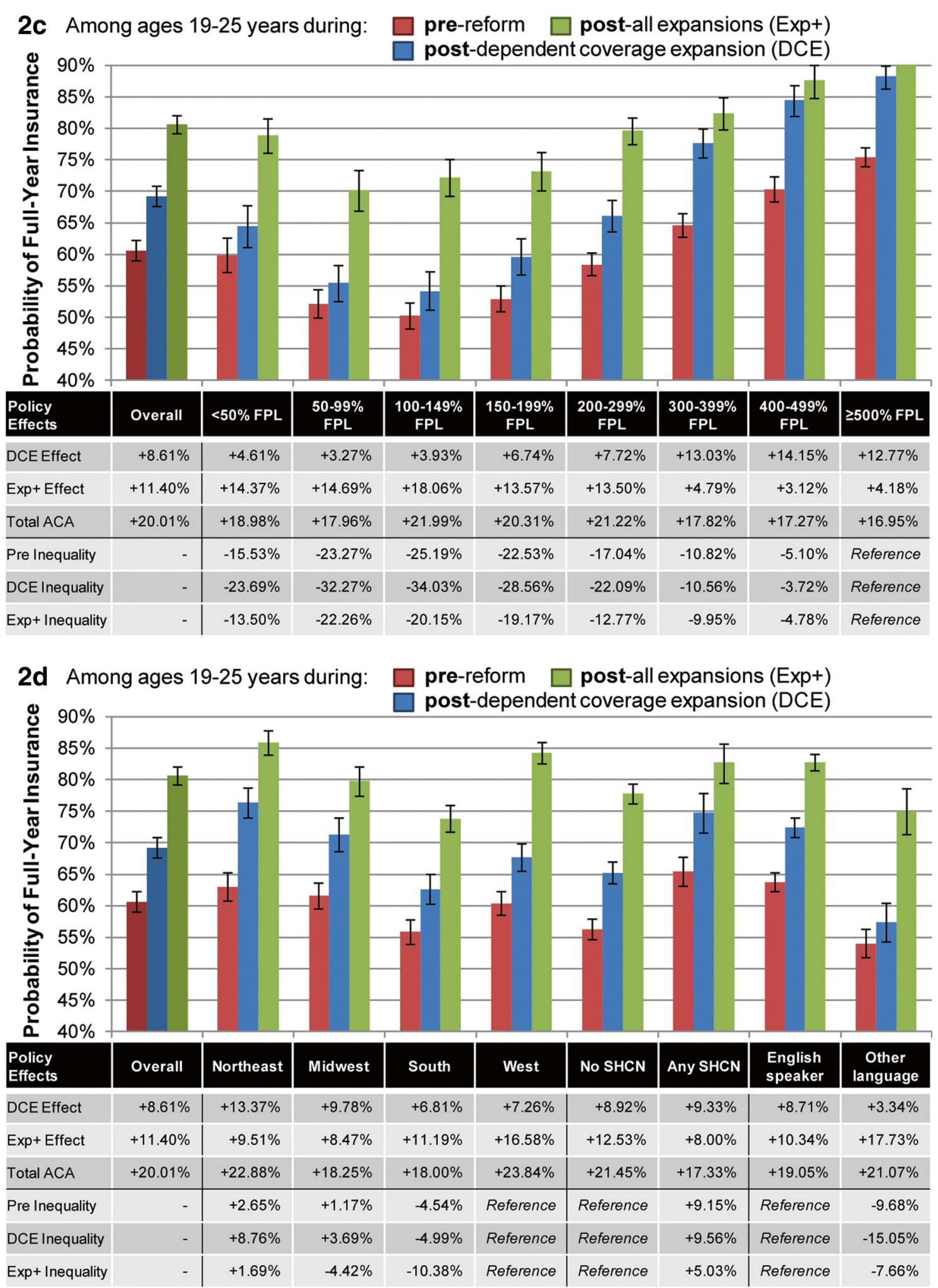

Figure 2 (continued)

should not be interpreted to suggest that disparities have been eliminated for AIAN but rather that disparities may not be widening for this group as a whole. Further, because AIAN may be more likely to be of lower SES, ${ }^{38}$ this group may still experience widening disparities (causally) owing to their income or education, rather than resulting directly from their racial identity. The observed inequities in policy gains for other minorities are particularly concerning for these same reasons, as these groups may experience worse rates of coverage because of both their race/ethnicity and stemming from their socioeconomic situation, further compounding already precarious access to coverage. 


\section{Limitations}

Several limitations should be considered when interpreting our findings. First, our data are cross-sectional and reflect insurance only over a 12-month period, so we do not have the ability to determine longitudinal changes in coverage that result from health reform. Thus, our study can provide new evidence about the impact of the ACA on full-year coverage but not on changes in coverage types over time. Second, given that this survey does not include the state of residence of participants for privacy reasons, we cannot identify individuals who lived in states that had previously enacted state-level dependent coverage expansions or that enacted Medicaid expansion; despite proxy adjustment using region of residence, we likely underestimate the specific policy effects for both the federal dependent coverage and Medicaid expansions. Finally, although we adjusted for several detailed sociodemographic characteristics, there may be other important factors (either between age groups or over time) whose omission from our models resulted in residual confounding. Despite these limitations, this investigation of inequalities in coverage gains for YA post-ACA represents a robust examination of detailed sociodemographic characteristics in order to isolate the drivers of disparities, thereby identifying opportunities for policy intervention.

\section{CONCLUSION}

We find evidence that federal health policy changes significantly impacted YA insurance coverage overall. Despite important absolute increases in rates of insurance coverage resulting from the ACA, these gains were not universally observed for all YAs, most notably including youth of lower socioeconomic status, and disparities in coverage remain. As such, more work involving both policy modifications and public health outreach needs to be done to ensure optimal and equitable access to high quality, affordable coverage for all YAs. Continued examination of long-term trends will be important for monitoring the impact of the ACA and any future health policies on YA coverage, access, and health.

\section{Acknowledgments:}

We wish to thank the anonymous reviewers for their helpful comments which greatly improved the content of this paper. We presented earlier versions of the manuscript at the Society for General Internal Medicine meeting (Denver, 2018) and the Society for Adolescent Health and Medicine meeting (Seattle, 2018).

Support: This work was financially supported by the Office of Faculty Development (OFD)/Basic/Translational Executive Committee (BTREC)/Clinical and Translational Research Executive Committee (CTREC) Faculty Career Development Fellowship 400384 (PI: Wisk) and Agency for Healthcare Research and Quality K12HSO22986 (PI: Finkelstein).

Corresponding Author: Lauren E. Wisk, PhD; Division of Adolescent/Young Adult Medicine, Boston Children's Hospital and Department of Pediatrics, Harvard Medical School, Boston, MA, USA (e-mail: lauren.wisk@childrens.harvard.edu).

\section{Compliance with Ethical Standards:}

Disclaimer: The content of this article is solely the responsibility of the authors and does not necessarily represent the official views of the Agency for Healthcare Research and Quality.

Conflict of Interest: The authors declare that they do not have a conflict of interest.

\section{REFERENCES}

1. Clarke TC, Norris T, Schiller JS. Early release of selected estimates based on data from the 2016 National Health Interview Survey. National Center for Health Statistics; 2017. Available at: https://www.cdc.gov/nchs/data/ nhis/earlyrelease/earlyrelease201705.pdf. Accessed 27 Nov 2017.

2. Callahan ST, Cooper wo. Uninsurance and health care access among young adults in the United States. Pediatrics. 2005;116(1):88-95.

3. Majerol M, Newkirk V, Garfield R. The uninsured: a primer - key facts about health insurance and the uninsured in America. Menlo Park: Kaiser Family Foundation; 2015.

4. Sommers BD, Kronick R. The Affordable Care Act and insurance coverage for young adults. JAMA. 2012;307(9):913-914.

5. Wisk LE, Finkelstein JA, Toomey SL, Sawicki GS, Schuster MA, Galbraith AA. Impact of an individual mandate and other health reforms on dependent coverage for adolescents and young adults. Health Serv Res. 2018;53(3):1581-1599.

6. McMorrow S, Kenney GM, Long SK, Anderson N. Uninsurance among young adults continues to decline, particularly in Medicaid expansion states. Health Aff. 2015;34(4):616-620.

7. Buchmueller TC, Levinson ZM, Levy HG, Wolfe BL. Effect of the Affordable Care Act on Racial and Ethnic Disparities in Health Insurance Coverage. Am J Pub Health. 2016;106(8):1416-1421.

8. Chen J, Vargas-Bustamante A, Mortensen K, Ortega AN. Racial and ethnic disparities in health care access and utilization under the affordable care act. Med Care. 2016;54(2):140-146.

9. Gonzales S, Sommers BD. Intra-ethnic coverage disparities among latinos and the effects of health reform. Health Serv Res. 2018;53(3):1373-1386.

10. Griffith $\mathbf{K}$, Evans $\mathbf{L}$, Bor J. The affordable care act reduced socioeconomic disparities in health care access. Health Aff. 2017. https://doi. org/10.1377/hlthaff.2017.0083.

11. Hayes SL, Riley P, Radley DC, McCarthy D. Reducing racial and ethnic disparities in access to care: has the affordable care act made a difference?. Issue Brief (Commonw Fund). 2017;20171-14.

12. Kennedy J, Wood EG, Frieden L. Disparities in insurance coverage, health services use, and access following implementation of the affordable care act: a comparison of disabled and nondisabled working-age adults. Inquiry. 2017;54:46958017734031.

13. Look KA, Kim NH, Arora P. Effects of the affordable care act's dependent coverage mandate on private health insurance coverage in urban and rural areas. J Rural Health. 2017;33(1):5-11.

14. Lipton BJ, Decker SL, Sommers BD. The affordable care act appears to have narrowed racial and ethnic disparities in insurance coverage and access to care among young adults. Med Care Res Rev. 2017:1077558717706575. https://doi.org/10.1177/1077558717706575.

15. Blewett LA, Drew JAR, Griffin R, King ML, Williams K. IPUMS Health Surveys: National Health Interview Survey, Version 6.2. Minneapolis: University of Minnesota; 2016.

16. United States Census Bureau. Current Population Survey (CPS) Health Insurance Definitions. Glossary. Available at: https://www.census.gov/topics/ health/health-insurance/about/glossary.htmlf. Accessed 24 March 2016.

17. Buchmueller TC, Monheit AC. Employer-sponsored health insurance and the promise of health insurance reform. Inquiry. 2009;46(2):187202.

18. Wong CA, Asch DA, Vinoya CM, et al. The experience of young adults on HealthCare.gov: suggestions for improvement. Ann Intern Med. 2014;161(3):231-232.

19. Busch SH, Golberstein E, Meara E. ACA dependent coverage provision reduced high out-of-pocket health care spending for young adults. Health Aff. 2014;33(8):1361-1366.

20. Chen J, Vargas-Bustamante A, Novak P. Reducing young adults' health care spending through the aca expansion of dependent coverage. Health Serv Res. 2017;52(5):1835-1857.

21. Chua KP, Sommers BD. Changes in health and medical spending among young adults under health reform. JAMA. 2014;311(23):2437-2439. 
22. Mulcahy A, Harris $\mathbf{K}$, Finegold $\mathbf{K}$, Kellermann A, Edelman $\mathbf{L}$, Sommers BD. Insurance coverage of emergency care for young adults under health reform. N Engl J Med. 2013;368(22):2105-2112.

23. Akosa Antwi Y, Moriya AS, Simon K, Sommers BD. Changes in emergency department use among young adults after the patient protection and affordable care act's dependent coverage provision. Ann Emerg Med. 2015;65(6):664-672 e662.

24. Barbaresco S, Courtemanche CJ, Qi Y. Impacts of the Affordable Care Act dependent coverage provision on health-related outcomes of young adults. J Health Econ. 2015;40:54-68.

25. Blum AB, Kleinman LC, Starfield B, Ross JS. Impact of state laws that extend eligibility for parents' health insurance coverage to young adults. Pediatrics. 2012;129(3):426-432.

26. Han X, Yabroff KR, Robbins AS, Zheng Z, Jemal A. Dependent coverage and use of preventive care under the Affordable Care Act. N Engl J Med. 2014;371(24):2341-2342

27. Lipton BJ, Decker SL. ACA provisions associated with increase in percentage of young adult women initiating and completing The HPV vaccine. Health Aff. 2015;34(5):757-764.

28. Robbins AS, Han $\mathbf{X}$, Ward EM, Simard EP, Zheng $\mathbf{Z}$, Jemal A. Association between the Affordable Care Act dependent coverage expansion and cervical cancer stage and treatment in young women. JAMA. 2015;314(20):2189-2191.

29. Sommers BD, Buchmueller T, Decker SL, Carey C, Kronick R. The Affordable Care Act has led to significant gains in health insurance and access to care for young adults. Health Aff. 2013;32(1):165-174.

30. Sommers BD, Blendon RJ, Orav EJ, Epstein AM. Changes in utilization and health among low-income adults after medicaid expansion or expanded private insurance. JAMA Intern Med. 2016;176(10):15011509.

31. Galbraith AA, Wong ST, Kim SE, Newacheck PW. Out-of-pocket financial burden for low-income families with children: socioeconomic disparities and effects of insurance. Health Serv Res. 2005;40(6 Pt 1):1722-1736

32. Wisk LE, Gangnon R, Vanness DJ, Galbraith AA, Mullahy J, Witt WP. Development of a novel, objective measure of health care-related financial burden for U.S. families with children. Health Serv Res. 2014;49(6):18521874.

33. Wisk LE, Witt WP. Predictors of delayed or forgone needed health care for families with children. Pediatrics. 2012;130(6):1027-1037.

34. Harris SK, Aalsma MC, Weitzman ER, et al. Research on clinical preventive services for adolescents and young adults: where are we and where do we need to go?. J Adolesc Health. 2017;60(3):249-260.

35. Wisk LE, Finkelstein JA, Sawicki GS, et al. Predictors of timing of transfer from pediatric- to adult-focused primary care. JAMA Pediatr. 2015;169(6):e150951.

36. Pande AH, Ross-Degnan D, Zaslavsky AM, Salomon JA. Effects of healthcare reforms on coverage, access, and disparities: quasiexperimental analysis of evidence from Massachusetts: Am J Prev Med. 2011;41(1):1-8.

37. Grace AM, Horn I, Hall R, Cheng TL. Children, families, and disparities: pediatric provisions in the Affordable Care Act: Pediatr Clin N Am. 2015;62(5): 1297-1311.

38. Castor ML, Smyser MS, Taualii MM, Park AN, Lawson SA, Forquera RA. A nationwide population-based study identifying health disparities between American Indians/Alaska Natives and the general populations living in select urban counties. Am J Public Health. 2006;96(8):14781484 .

\section{APPENDIX}

Table 2 Sample Sociodemographics and Insurance Coverage, by Age

\begin{tabular}{|c|c|c|c|c|c|c|}
\hline & Total $^{a}$ & Ages $13-18$ years & Ages 19-25 years & Ages 26-30 years & Full-year insured $^{b}$ & $p$ value $^{\tau}$ \\
\hline Total $N$ (unweighted) & 387,635 & 140,639 & 141,755 & 105,241 & & \\
\hline Total \% (weighted) & & $33.9 \%$ & $38.8 \%$ & $27.3 \%$ & $70.6 \%$ & \\
\hline \multicolumn{7}{|l|}{ Sociodemographics } \\
\hline Sex & & & & & & $<0.001$ \\
\hline Male & $50.3 \%$ & $51.1 \%$ & $50.1 \%$ & $49.5 \%$ & $68.3 \%$ & \\
\hline Female & $49.7 \%$ & $48.9 \%$ & $49.9 \%$ & $50.5 \%$ & $73.0 \%$ & \\
\hline Race/ethnicity & & & & & & $<0.001$ \\
\hline White, non-Hispanic & $60.7 \%$ & $60.5 \%$ & $61.0 \%$ & $60.6 \%$ & $75.9 \%$ & Ref \\
\hline Black, non-Hispanic & $14.1 \%$ & $15.0 \%$ & $14.2 \%$ & $13.0 \%$ & $70.1 \%$ & $* * *$ \\
\hline Chinese, non-Hispanic & $0.9 \%$ & $0.8 \%$ & $1.0 \%$ & $1.1 \%$ & $76.3 \%$ & \\
\hline Filipino, non-Hispanic & $0.9 \%$ & $0.9 \%$ & $0.9 \%$ & $1.0 \%$ & $79.5 \%$ & $* *$ \\
\hline Asian Indian, non-Hispanic & $1.1 \%$ & $0.7 \%$ & $1.0 \%$ & $1.8 \%$ & $79.3 \%$ & $*$ \\
\hline Other Asian, non-Hispanic & $1.9 \%$ & $1.7 \%$ & $1.9 \%$ & $2.0 \%$ & $72.8 \%$ & $* *$ \\
\hline AIAN, non-Hispanic & $0.8 \%$ & $0.9 \%$ & $0.8 \%$ & $0.7 \%$ & $54.3 \%$ & $* * *$ \\
\hline Other, non-Hispanic & $0.3 \%$ & $0.3 \%$ & $0.3 \%$ & $0.2 \%$ & $70.2 \%$ & $*$ \\
\hline Multiple, non-Hispanic & $0.3 \%$ & $0.5 \%$ & $0.3 \%$ & $0.2 \%$ & $73.1 \%$ & \\
\hline Mexican-Americans & $12.7 \%$ & $12.6 \%$ & $12.5 \%$ & $12.9 \%$ & $47.7 \%$ & $* * *$ \\
\hline Other Hispanic & $6.3 \%$ & $6.2 \%$ & $6.2 \%$ & $6.4 \%$ & $59.1 \%$ & $* * *$ \\
\hline Citizenship status & & & & & & $<0.001$ \\
\hline Born in US (or territories) & $86.6 \%$ & $92.3 \%$ & $86.2 \%$ & $80.0 \%$ & $74.3 \%$ & Ref \\
\hline Naturalized/legal citizen & $3.7 \%$ & $2.3 \%$ & $3.8 \%$ & $5.5 \%$ & $69.5 \%$ & $* * *$ \\
\hline Not a citizen & $9.1 \%$ & $5.0 \%$ & $9.5 \%$ & $13.7 \%$ & $39.4 \%$ & $* * *$ \\
\hline Unknown & $0.6 \%$ & $0.4 \%$ & $0.6 \%$ & $0.7 \%$ & $54.8 \%$ & $* * *$ \\
\hline Interview language & & & & & & $<0.001$ \\
\hline English only & $90.5 \%$ & $90.2 \%$ & $90.8 \%$ & $90.5 \%$ & $73.4 \%$ & Ref \\
\hline Any other & $7.8 \%$ & $7.9 \%$ & $7.5 \%$ & $8.0 \%$ & $38.1 \%$ & $* * *$ \\
\hline Unknown & $1.7 \%$ & $1.9 \%$ & $1.7 \%$ & $1.5 \%$ & $70.7 \%$ & $* * *$ \\
\hline Educational attainment & & & & & & $<0.001$ \\
\hline No high school diploma & $15.3 \%$ & $20.6 \%$ & $12.7 \%$ & $12.4 \%$ & $52.9 \%$ & $* * *$ \\
\hline HS grad or GED & $25.6 \%$ & $23.7 \%$ & $28.1 \%$ & $24.4 \%$ & $64.2 \%$ & $* * *$ \\
\hline Some college, no degree & $25.1 \%$ & $17.2 \%$ & $36.4 \%$ & $18.9 \%$ & $74.2 \%$ & $* * *$ \\
\hline Associates/vocational degree & $9.4 \%$ & $10.5 \%$ & $7.5 \%$ & $10.7 \%$ & $76.8 \%$ & $* * *$ \\
\hline Bachelor's degree & $16.6 \%$ & $16.0 \%$ & $12.6 \%$ & $23.1 \%$ & $84.1 \%$ & Ref \\
\hline Graduate degree & $6.4 \%$ & $10.7 \%$ & $1.36 \%$ & $8.5 \%$ & $91.4 \%$ & $* * *$ \\
\hline Unknown & $1.5 \%$ & $1.2 \%$ & $1.4 \%$ & $1.9 \%$ & $62.7 \%$ & $* * *$ \\
\hline
\end{tabular}


Table 2. (continued)

\begin{tabular}{|c|c|c|c|c|c|c|}
\hline & Total $^{a}$ & Ages 13-18 years & Ages 19-25 years & Ages 26-30 years & Full-year insured $^{b}$ & $p$ value ${ }^{\mathrm{c}}$ \\
\hline \multicolumn{6}{|l|}{ Family income } & $<0.001$ \\
\hline Less than $50 \%$ FPL & $8.1 \%$ & $7.3 \%$ & $10.6 \%$ & $5.8 \%$ & $61.2 \%$ & $* * *$ \\
\hline $50-99 \%$ FPL & $10.3 \%$ & $10.6 \%$ & $11.4 \%$ & $8.4 \%$ & $55.2 \%$ & $* * *$ \\
\hline 100-149\% FPL & $11.1 \%$ & $11.1 \%$ & $11.8 \%$ & $10.0 \%$ & $54.4 \%$ & $* * *$ \\
\hline $150-199 \%$ FPL & $10.0 \%$ & $9.8 \%$ & $10.4 \%$ & $9.6 \%$ & $58.8 \%$ & $* * *$ \\
\hline $200-299 \%$ FPL & $18.1 \%$ & $17.9 \%$ & $18.2 \%$ & $18.1 \%$ & $68.4 \%$ & $* * *$ \\
\hline 300-399\% FPL & $12.4 \%$ & $12.6 \%$ & $11.5 \%$ & $13.5 \%$ & $77.3 \%$ & $* * *$ \\
\hline 400-499\% FPL & $9.0 \%$ & $9.1 \%$ & $8.1 \%$ & $10.4 \%$ & $82.8 \%$ & $* * *$ \\
\hline $500 \%+$ FPL & $20.3 \%$ & $20.9 \%$ & $17.4 \%$ & $23.7 \%$ & $87.8 \%$ & Ref \\
\hline Unknown & $0.6 \%$ & $0.7 \%$ & $0.6 \%$ & $0.6 \%$ & $67.5 \%$ & $* * *$ \\
\hline \multicolumn{6}{|l|}{ Region of residence } & 0.001 \\
\hline Northeast & $17.2 \%$ & $17.7 \%$ & $17.3 \%$ & $16.4 \%$ & $76.9 \%$ & $* * *$ \\
\hline Midwest & $23.4 \%$ & $23.4 \%$ & $23.7 \%$ & $23.0 \%$ & $75.0 \%$ & $* * *$ \\
\hline South & $36.4 \%$ & $36.0 \%$ & $36.4 \%$ & $36.9 \%$ & $66.3 \%$ & $* *$ \\
\hline West & $23.0 \%$ & $23.0 \%$ & $22.6 \%$ & $23.7 \%$ & $68.0 \%$ & Ref \\
\hline \multicolumn{6}{|l|}{ Special health care needs } & $<0.001$ \\
\hline None & $93.9 \%$ & $91.6 \%$ & $95.2 \%$ & $94.9 \%$ & $70.3 \%$ & \\
\hline Any & $6.1 \%$ & $8.4 \%$ & $4.8 \%$ & $5.1 \%$ & $75.5 \%$ & \\
\hline \multicolumn{7}{|l|}{ Insurance coverage } \\
\hline \multicolumn{7}{|l|}{ Annual coverage summary } \\
\hline Full-year insured & $72.5 \%$ & $85.6 \%$ & $65.0 \%$ & $66.8 \%$ & & \\
\hline Partial-year insured & $12.5 \%$ & $7.0 \%$ & $15.3 \%$ & $13.8 \%$ & & \\
\hline Full-year uninsured & $15.4 \%$ & $7.4 \%$ & $19.6 \%$ & $19.4 \%$ & & \\
\hline Any private coverage & $61.0 \%$ & $63.2 \%$ & $58.5 \%$ & $61.9 \%$ & & \\
\hline Full-year coverage ${ }^{\mathrm{d}}$ & $93.7 \%$ & $97.4 \%$ & $91.7 \%$ & $91.6 \%$ & & \\
\hline Employer-sponsored $^{\mathrm{d}}$ & $91.0 \%$ & $92.5 \%$ & $89.4 \%$ & $91.3 \%$ & & \\
\hline Non-group market ${ }^{\mathrm{d}}$ & $6.8 \%$ & $6.0 \%$ & $7.5 \%$ & $6.8 \%$ & & \\
\hline Marketplace $(2014+)^{\mathrm{d}}$ & $4.6 \%$ & $3.5 \%$ & $4.4 \%$ & $6.2 \%$ & & \\
\hline Any government coverage & $18.1 \%$ & $27.1 \%$ & $14.2 \%$ & $12.5 \%$ & & \\
\hline Full-year coverage $\mathrm{e}^{\mathrm{e}}$ & $89.1 \%$ & $93.2 \%$ & $84.9 \%$ & $85.0 \%$ & & \\
\hline $\mathrm{CHIP} / \mathrm{SCHIP}{ }^{\mathrm{e}}$ & $8.5 \%$ & $15.2 \%$ & $1.8 \%$ & $1.6 \%$ & & \\
\hline Medicaid $^{\mathrm{e}}$ & $71.0 \%$ & $69.2 \%$ & $73.2 \%$ & $72.5 \%$ & & \\
\hline Other state/federal ${ }^{\mathrm{e}}$ & $11.3 \%$ & $8.4 \%$ & $12.6 \%$ & $17.1 \%$ & & \\
\hline Military ${ }^{\mathrm{e}}$ & $10.5 \%$ & $7.9 \%$ & $13.9 \%$ & $12.3 \%$ & & \\
\hline \multicolumn{7}{|l|}{ Reason(s) uninsured ${ }^{f}$} \\
\hline Ineligible $\mathrm{b} / \mathrm{c}$ of age/left school & $19.2 \%$ & $6.9 \%$ & $28.4 \%$ & $11.2 \%$ & & \\
\hline Cost is too high & $42.3 \%$ & $47.6 \%$ & $38.6 \%$ & $45.4 \%$ & & \\
\hline Major life event & $26.2 \%$ & $12.2 \%$ & $35.4 \%$ & $19.2 \%$ & & \\
\hline
\end{tabular}

AIAN, American Indian/Alaskan Native; CHIP/SCHIP, Children's Health Insurance Program/State Children's Health Insurance Program; FPL, federal poverty level; GED, general educational development; HS, high school

${ }^{a}$ Total and age group columns are reported as column percent for the entire study period

${ }^{b}$ Full-year insured during the pre-reform period among the full sample (all ages) reported as row percent

${ }^{c} p$ value compares rates of full-year insured to any lapse (in the pre-reform period) by sociodemographic characteristics and comparing each category against the specified reference group $(* p<0.05, * * p<0.01, * * * p<0.001)$

${ }^{d}$ Prevalence reported is among those with any private insurance coverage $(N=217,885)$

${ }^{e}$ Prevalence reported is among those with any government insurance coverage $(N=79,200)$

${ }^{f}$ Prevalence reported is among those uninsured at the time of the survey $(N=89,715)$; groups are not mutually exclusive or exhaustive

Data are from the 2000-2016 National Health Interview Survey. All estimates are weighted to be nationally representative 